\title{
Effects of Credit Risk and Banking Supervision on The Access to Credit in a Dualistic Economy: The Case of Southern Italy
}

\author{
Cesare Imbriani \\ UniTelma Sapienza - Università degli studi di Roma \\ Antonio Lopes \\ Università degli Studi di Napoli "L'Orientale"
}

In this article the authors discuss the effects of changes in bank regulation on the behavior of banks as regards their willingness to finance companies in Italy and in Southern Italy in particular. They at first examine the evolution of the Supervisory banking model and its impact on a dualistic economy like Southern Italy; then provide a statistical evidence of the access to credit in Italy according to different areas and regions and different bank size; finally, they conclude with some policy implications about the reshaping a virtuous relationship between banks and firms in Southern Italy.

Keywords: Supervision, Banks, Southern Italy

\section{SHIRINKING MANUFACTURING SECTOR AND CREDIT RISK INCREASING}

Since 2008, the impacts of the European financial crisis have been deep and diversified among both the countries of European area and Italian regions.

Among the European States, Germany's GDP has increased by 12,3\% between 2008 and 2017, France one by $8 \%$, Spain one by $2,8 \%$, by contrast Greece and Italy contracted by $25,4 \%$ and $5,5 \%$ respectively. Moreover, Italian Southern area (so called Mezzogiorno) GDP decreased by 10\% against a 4,1\% decrease in the Centre-North (Banca d'Italia, 2018a, pp. 5-6).

Thus, the crisis deepened the macroeconomic imbalances among countries and regions belonging to the Eurozone, which were already displayed when the European Monetary Union was established.

According to several scholars (Myrdal, 1957, 1958; Krugman \& Venables, 1990, 1995; Krugman, 1991; Kaldor, 1970; Dixon \& Thirlwall, 1975), through the triggering of cumulative processes, free market mechanisms may generate divergences among these countries and regions that have a common currency - but different economic and social structures -, thus resulting in the reinforcement of any and the weakening of others. Concerning Italian economy, crisis highlighted the internal divide between Southern regions and Centre-Northern most dynamic areas: just to give some numbers, between 2007 and 2016, the firms with a number of employees range between 10 and 250 decreased by $6,2 \%$ in Southern Italy versus a reduction of $2,3 \%$ in the rest of the country, as shown in the 2018 reports on the situation of SMEs in the Centre-North and the Southern Italy published by Cerved - Confindustria.

Moreover, although the economic crisis has strengthened the productive system by eliminating the most inefficient firms, the remaining ones have different problems in surviving, growing and relating to 
the banking system, given the weak social and institutional context. The severity of the crisis and the reduction of resources and opportunities, together with the downturn in domestic demand, have been factors contributing to deplete the productive system of Southern Italy, consequently increasing the risk profiles for banks. According to the classification of the financial statements realized by Cerved, reported in TABLE 1, it is possible to notice that the reduction of the enterprises caused by the crisis determined, between 2007 and 2017, a lower increasing of the small and medium classified as "solvent" enterprises in the South than the rest of Italy: respectively $+17 \%$ against $+27,8 \%$.

At the same time the enterprises with a "vulnerable" budget have decreased by $-5,7 \%$ in the South against a $-12,5 \%$ reduction in the Centre-North; finally, the percentage of companies at risk of bankruptcy has reduced by $-11,3 \%$ in the South against a higher reduction, by $-15,4 \%$, in the rest of the Country. These evidences show that the long recession has caused a polarization of SMEs financial performances between the two areas. In fact, until the end of 2017, just the $48,4 \%$ of firms in the South could be classified as solvent against the $68,8 \%$ in the Centre-north; conversely, the vulnerable and firms at risk of bankruptcy in the South respectively represent the $35,4 \%$ and $16,2 \%$ against the $21,9 \%$ and $9,3 \%$ in the Centre-north. This means that Southern firms are potentially less likely to be financed by banks, even considering the very restrictive criterions imposed by both the Regulator and the supervisory model imposed to financial intermediaries, as reported in TABLE 1.

TABLE 1

FINANCIAL ECONOMIC SCORE OF ACTIVE SMALL AND MEDIUM ENTERPRISES (SME) (\% VALUES)

\begin{tabular}{|l|rrr|rrr|rrr|}
\hline \multirow{2}{*}{ Areas } & \multicolumn{3}{|c|}{2007} & \multicolumn{3}{c|}{2017} & \multicolumn{3}{c|}{$\%$ 2007-2017 } \\
\cline { 2 - 11 } & Solvent & Vulnerable $\begin{array}{c}\text { Bankruptcy } \\
\text { Risk }\end{array}$ & Solvent & Vulnerable $\begin{array}{c}\text { Bankruptcy } \\
\text { Risk }\end{array}$ & Solvent & Vulnerable $\begin{array}{c}\text { Bankruptcy } \\
\text { Risk }\end{array}$ \\
\hline Centre-North & 41,0 & 34,4 & 24,7 & 68,8 & 21,9 & 9,3 & 27,8 & $-12,5$ & $-15,4$ \\
\hline Southern Italy & 31,4 & 41,1 & 27,5 & 48,4 & 35,4 & 16,2 & 17,0 & $-5,7$ & $-11,3$ \\
\hline Italy & 39,8 & 35,4 & 24,8 & 63,7 & 25,3 & 11,0 & 23,9 & $-10,1$ & $-13,8$ \\
\hline
\end{tabular}

Source: Our elaboration on data by "Cerved-Confindustria Centro-Nord e Mezzogiorno", 2018.

In the light of these data, in this article we will discuss the effects of changes in bank regulation on the behavior of banks as regards their willingness to finance companies in Italy and in Southern Italy in particular. The paper is organized as follows: in section 2 we discuss the evolution of the Supervisory banking model and its impact on a dualistic economy like Southern Italy; in section 3 we provide a statistical evidence of the access to credit in Italy according to different areas and regions and different bank size; finally, section 4 concludes with some policy implications about the reshaping a virtuous relationship between banks and firms in Southern Italy.

\section{CHANGES IN SUPERVISORY BANKING MODEL AND IMPACT ON A DUALISTIC ECONOMY LIKE SOUTHERN ITALY}

In the last years, together with the increased risk faced by the banks in an area characterized by a relevant deterioration of the macroeconomic features, important changes have been made to the supervisory model, by setting further constraints to the banking activity.

The reforms launched after the international financial crisis directly derived from the Regulator requirements, asking for more caution in the agent decisions. In particular, the attention of the regulation systems has grown, with reference to both the prudential profiles (capital, liquidity, financial leverage) and the compliance, through the rules directed to ensure the transparency and the fairness of banks 
behaviour towards the costumers. Currently, the evaluation of these interventions is subject of a debate, dealing with both the ability of the banking system to face an external shock and the effects that these further constraints could have on the banking activity by restricting its scope, with negative consequences on the accumulation processes.

A large body of theoretical and empirical research has documented how exogenous changes in bank capital may affect lending conditions and, in turn, economic activity. One key channel highlighted in the literature underscores that when bank capital constraints become tighter, intermediaries react by curtailing the availability of loans, increasing lending spreads and changing the composition of assets; the tighter credit supply conditions negatively affect firms' income, investment and employment (Conti, et al., 2018).

Basel III agreements represent an answer to the financial market's turmoil following the 2008 crisis. In December 2009, the Basel Committee on Banking Supervision published a consultation document with concrete proposals for capital and liquidity regulatory reforms (Basel Committee on Banking Supervision, 2009). The final text of the Basel III reform was approved at the end of 2010 (Basel Committee on Banking Supervision, 2010). The details of the reform were largely anticipated by the banks, who started increasing their capital buffers as soon as the discussion started. In the period considered, the Tier 1 equity of Italian banks increased by an aggregate amount of 24 billion, about $16 \%$ of the initial level of capital. In this framework the Tier 1 capital ratio is a key regulatory measure of a bank's capital adequacy. The numerator (Tier 1 capital) consists of Common Equity Tier 1 (CET1) - i.e., common shares, stock surpluses resulting from the issue of common shares, retained earnings, common shares issued by subsidiaries and held by third parties, accumulated other comprehensive income (AOCI) - and Additional Tier 1 capital (AT1) - which includes instruments that are not common equity but are eligible to be included in this tier, such as contingent convertible or hybrid securities, which have a perpetual term and can be converted into equity when a trigger event occurs. The denominator consists of RWAs that are total bank assets (including off-balance-sheet exposures) weighted according to their riskiness.

The new regulation acts on various sectors by introducing increasingly severe constraints: from the tightening of the capital criterion, to the risks coverage and the introduction of stricter liquidity requirements (Banca d'Italia, 2018b, pp. 44-49).

We can say that in recent years, in Europe, a unified approach towards the banking regulation has prevailed, compared to United States: this approach does not consider the differences between small and medium banks, based on a traditional business model, and the medium-large ones, representing a global target market; let alone regional banks, potentially achieving a comparative advantage in financing small local enterprises. Thus, although the sector of small and medium firms turns out to be the most relevant in terms of creation (and destruction) of employment in both Italy and Europe, it results the most penalized by this scheme of banking supervision (Masera, 2016). Another different point between the Europe and United States relies on both a strong and extended expansive impulse of monetary policy launched by FED and on direct interventions and public guarantees to reabsorb the stock of Non-Performing Loans (NPL) through extended forms of securitisation, different from the late BCE intervention (Imbriani \& Lopes, 2016; 2017; 2018).

In general, the introduction of global minimum coefficients of liquidity, perhaps the most innovative feature, had a significant impact on credit supply to the smaller enterprises.

In fact, with the new regulation, the capital absorption corresponding to the financings to SMEs is growing, as a consequence the provision of credit to these enterprises becomes more expensive for banks that have to conserve more resources in comparison to the previous regulation, this is a strong disincentive to finance a real economy. In conclusion, Basel III requires the payment of risk premiums, proportionate to both the riskiness of firm's business and the area in which they operate. Thus, since banks evaluate the enterprise based on its ability of coping with hazard in the market where it operates, SMEs will be inevitably adversely affected in the opportunities for loan financing, if they are not able to improve their risk management.

Moreover, in December 2017 the Basel Committee has defined the new standards for Basel IV and released the final rules for the calculation of the operational risk capital. The Committee mainly focused 
on the volatility in the calculation of the capital requirements from the banks that use internal models, thus introducing a new unique and not-model based methodology for the calculation of operational risk capital, with a standard approach that will be applied as from January $1^{\text {st }} 2022$.

The objective was to improve calculation comparability and simplicity. Thus, the reform will make the capital requirements defined by the previous of Basel Agreements even more rigid, adding further prescriptions on capital provisions: instead, it acts to limit the benefits of the internal model, through which big banks evaluate their own risks, by introducing the so called Output Floor, namely a minimum level of provisions, calculated as a percentage of those identified through the standard approach.

After months of negotiations, a level of $72,50 \%$ has been established, corresponding to the possibility of applying a discount rate not higher than $27,50 \%$ of the provision levels planned by the standard model. In other terms, banks using the risk evaluation based on internal models cannot have a benefit in terms of risk-weighted assets (RWA) for values up to $27,5 \%$.

In comparison to the standard model and to the discounts currently applied, which are higher on average, this discount consists of a request for larger provisions for covering the granted credits. That means a trade-off between the decision to either further increase their capital requirements or to limit credit provision, in order to reduce the assets in the balance sheet (Barucci \& Milani, 2017). This further changes in regulation must induce a greater awareness of the entrepreneurs, in order to favour a more balanced risk sharing between enterprises and banks: from one side, the reform can be an opportunity to re-assess the credit issue, decoupling it from the dependence on the banking system; it can also be an opportunity for the most dynamic and competitive enterprises; on the other side, for the smaller firms operating in more problematic contexts, the possibilities to access the credit become more limited.

In fact, if it is obvious that the banking intermediation will consolidate its fundamental role, it is likewise clear that the reduced banks availability should be replaced by alternative financial resources, which are not likely to be in range of all the enterprises, especially those operating in the weakest areas.

Moreover, the increasing use of the "guidelines", that are becoming more and more "prescriptive" for the banks, cannot be ignored. The recent case of the so-called BCE "addendum" is symbolic, concerning the management of NPL for large banks: it is likely to penalize Italian banks above all and to slow down the flow of the credit to the enterprises, in this delicate phase of the European economy (BCE, 2018). In every case, even if the European Union has recently recognized that the problem of the deteriorated credits of the banks must be dealt in European perspective, the traditional hostility toward any form of loss mutualisation implicates that the relative costs must be borne at Member State level (European Commission, 2017; Consiglio Europeo, 2017).

The consequence for the production system is twofold: firstly, a greater caution in the disbursement of credit to enterprises and households and, secondly, a consequent increase in the interest rates to account for the greater risk of credit. Therefore, the potential contradiction between the micro-prudential objectives of bank capital reinforcement, penalizing the ability of the banking system to finance the economy, and the macro-prudential ones of supporting the stability of the same banking system, is evident.

Conversely, it would be necessary to recognize that the advanced models of prudential regulation should be less complex and not penalizing for the retail banks of local and regional dimensions. Regulation should be proportional and articulated on the basis of both the dimensions and the activities developed by the banks; instead it is paradoxical to observe that, though the European financial system is mainly focused on the banking system than on financial markets, in the long term, European trend towards the concentration and the reduction of the credit institutes is stronger than United States one (just think of the 3,265 less significant European banks versus 5,538 US banks with Simplified Prudential Standards).

In conclusion, the approach "one-size-fits-all" should be modified, for eliminating a competitive disadvantage for the small banks, without any justification for the financial stability, penalizing the credit to households and smaller firms at local level. 


\section{BANKS AND TERRITORY; CRISIS AND ACCESS TO CREDIT}

As we have seen, the deterioration of the macroeconomic situation negatively affected the financial situation of companies, which in turn led to a progressive worsening of the credit. The banks responded, on the one hand, with more intense provisioning policies, on the request of regulators, and, on the other, with credit restrictions. Solid but illiquid companies have thus entered a vicious circle which, in the end, has further increased NPL.

The lack of homogeneity of monetary conditions in the euro area, more accentuated during the 20092013 period and partly reduced in the following four years, reflects negatively on the relationship between banks and firms: in Italy a progressive contraction of the trend of loans to businesses is experienced compared to the overall performance of the Euro zone countries. Symmetrically there is a stiffening of the conditions under which credit is granted: there is therefore a divergent trend in the dynamics of credit flows in the euro area between the large countries of Northern Europe and the peripheral countries of Southern Europe. In order to provide more information on the behavior of the banking system in Europe with regard to credit to the productive sector, the BLS data were compared with the questionnaires administered to Italian banks with data regarding the complex of banks belonging to the countries of the Euro zone; a positive value of the index means a tightening of the criteria; instead, a negative value indicates a relaxation of the latter; the answers reflect the lending policy of each bank characterized by its internal orientation.

FIGURE 1 shows the trend of the indicator (that for Italian banks is growing and tends to be higher than that observed for the whole of the Euro-zone banks for the 2008-2013 period, while the subsequent period sees Italian banks progressively easing the conditions for granting of loans, the indicator in fact stands at the levels prevailing for euro area banks.

FIGURE 1

\section{CRITERIA APPLIED BY BANKS FOR GRANTONG LOANS TO FIRMS (a)}

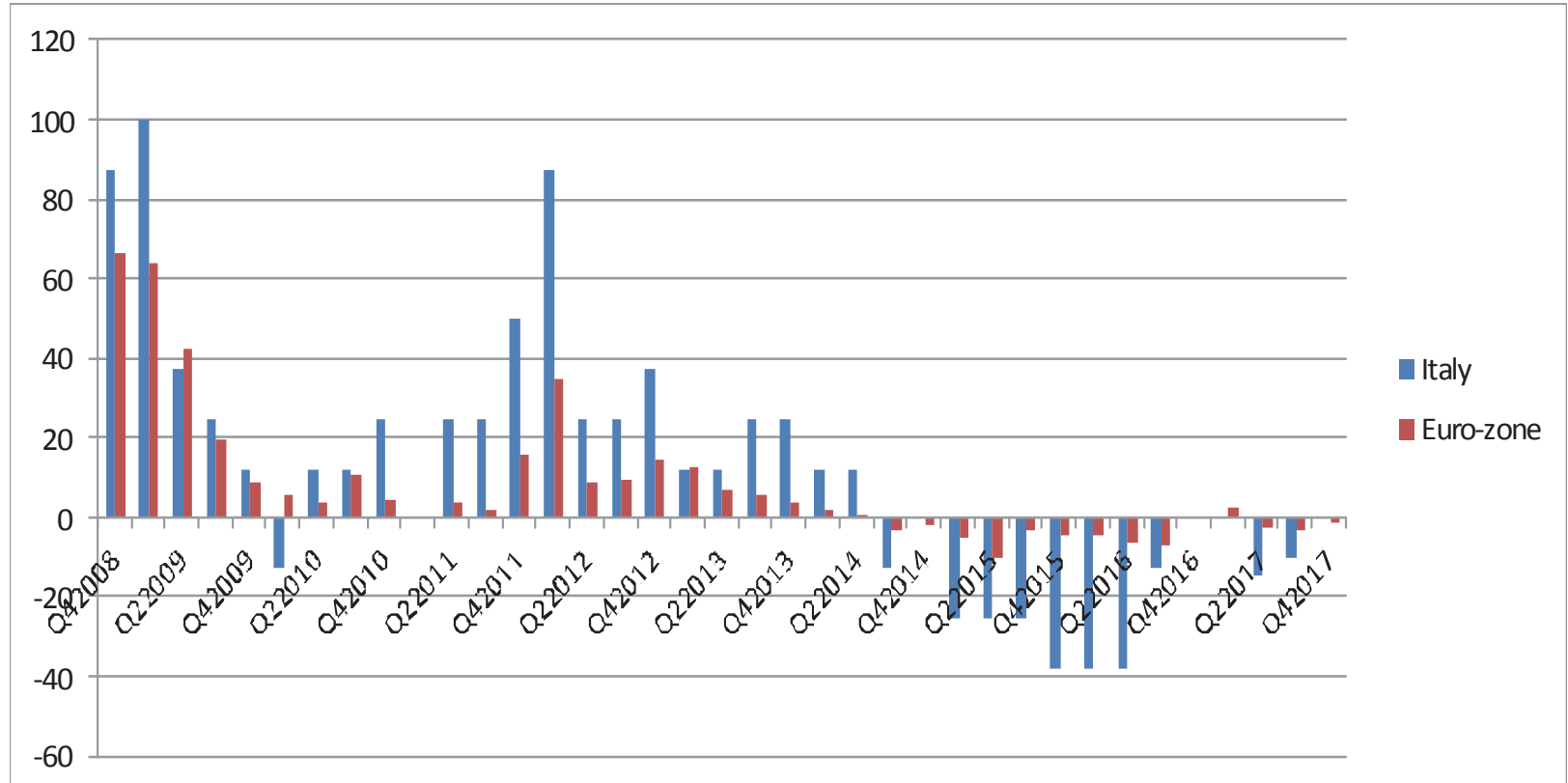

Source: Based on ECB BLS, various issues.

(a) Positive index indicates a tightening of the criteria; negative values their loosening. 
By other elaborations on data taken from Regional Bank Lending Survey by Bank of Italy (RBLS) ${ }^{1}$ more detailed information can be offered on the dynamics of the criteria applied by banks in Italy according different areas and bank dimension.

Looking at FIGURES 2 and 3, other indications can be found on the dynamics of the relationship between banks and companies operating in the two areas of the country as regards the credit conditions applied to the firms. Up to the first half of 2013 the first five banking groups have tightened the conditions for the granting credit to the Southern firms to a greater extent than they did for the companies located in the Centre-North. Subsequently, since the second half of 2013, the large groups have made the criteria for granting credit less stringent, but this relaxation is relatively more intense for banks operating in the Centre-North. It should also be noted that overall, since 2015, large groups are progressively limiting this more permissive attitude.

The picture offered by the other banks, which includes the smaller local banks operating in more limited markets, is partly different. In this case too, we observe that until 2013, the banks tightened the criteria for granting loans to a greater extent in the South compared to what happened in the rest of the country. However, from the second half of 2014 the relaxation of the criteria is generally more intense than for large groups; moreover, it is relatively more intense with respect to the Southern firms than it does in respect of the firms of the Centre-North, since in the South the banks are faced with a sample of companies already much more selected and reduced compared with other areas of the country.

FIGURE 2

CREDIT CONDITIONS APPLIED BY FIRST 5 LARGE BANKING GROUPS (a)

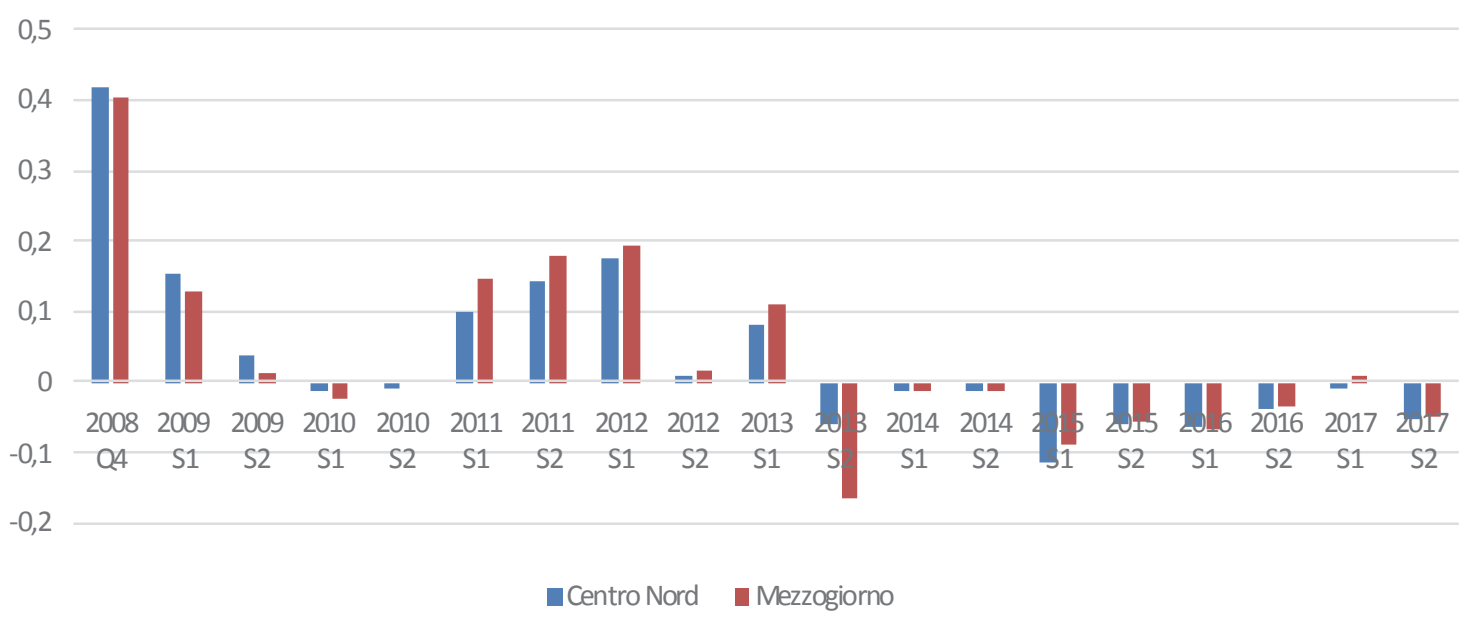

(a) Positive index indicates a tightening of the criteria; negative values their loosening. Source: Based on Banca d'Italia RBLS, various issues. 


\section{FIGURE 3}

\section{CREDIT CONDITIONS APPLIED BY OTHER BANKS (a)}

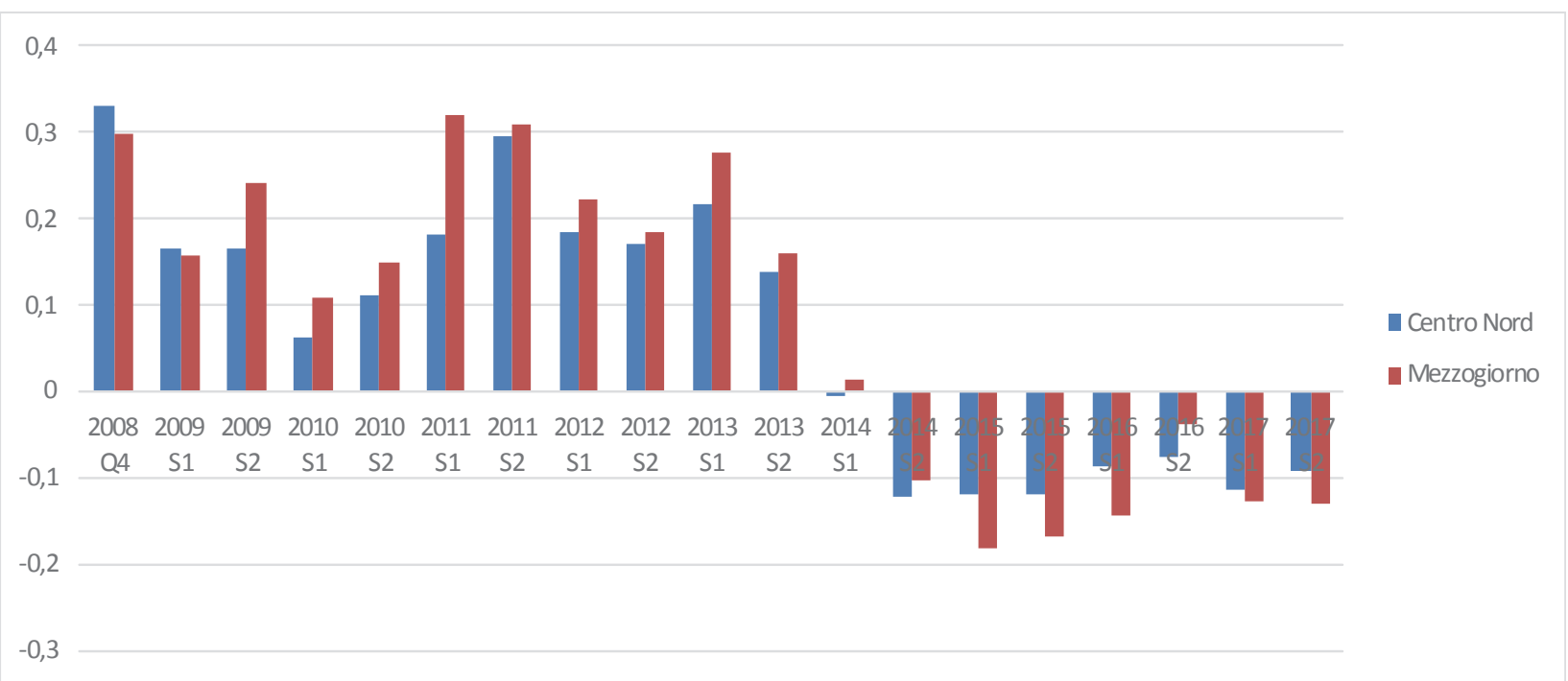

(a) Positive index indicates a tightening of the criteria; negative values their loosening. Source: Based on Banca d'Italia RBLS, various issues.

A further comparison can be carried out by analyzing loans growth rates, disaggregated according to the dimension of banks, in two areas. TABLE 2 shows that, on average, in 2013-2017 the first five groups have reduced the loans in all areas, mainly in the Centre-north regions. By considering the other large and medium size banks, in the same period, it can be noticed that they reduced credit more and more in the South than in the rest of the Country. Conversely in 2016-2017, a higher recovery of the banking loans was recorded in the Southern area. Moreover, the small sized banks have finally increased the expansion of the credit in the South to a greater extent than in the rest of the Country.

TABLE 2

LOANS ACCORDING BANK DIMENSION (\% ANNUAL CHANGE)

\begin{tabular}{cccccc}
\hline \multirow{2}{*}{ Areas } & \multicolumn{6}{c}{ First 5 banking groups } \\
\cline { 2 - 6 } & 2013 & 2014 & 2015 & 2016 & 2017 \\
\hline Centre- North & $-6,1$ & $-1,5$ & $-0,7$ & $-0,7$ & 1,0 \\
Southern Italy & $-3,3$ & -2 & 0,2 & 0,9 & $-0,2$ \\
Italy & $-5,6$ & $-1,6$ & $-0,6$ & $-0,4$ & 0,8 \\
\hline \multicolumn{5}{c}{ Others large and Medium size banks } \\
\hline Centre- North & 2013 & 2014 & 2015 & 2016 & 2017 \\
Southern Italy & $-1,9$ & 1,1 & 0,0 & 0,0 & 0,7 \\
Italy & $-2,5$ & $-2,1$ & $-0,4$ & 0,6 & 1,3 \\
& -2 & 0,7 & 0,0 & 0,1 & 0,8 \\
\hline Centre- North & -2013 & 2014 & 2015 & 2016 & 2017 \\
\hline Southern Italy & $-0,7$ & 0 & 0,5 & 2,6 & 4,2 \\
Italy & $-0,5$ & 1,9 & 1,2 & 3,0 & 4,6 \\
\hline
\end{tabular}

Source: Our Elaboration on data by Bank of Italy, Economie Regionali, different years. 
In conclusion, there has been a persistent role of the small-sized, locally rooted, banks in interacting with this fragile segment of enterprises heavily penalized by the non-performing loans.

Besides, in Southern Italy, the large-sized banks tend to both provide more funding to enterprises with higher rating than in the rest of the country and diversify their activity within the areas of trading and saving management, to a greater extent than local banks. Other indications of credit rationing effect can be drawn by the annual survey on the industrial enterprises and services realized by Bank of Italy, as reported in TABLE 3.

On average, between 2011 and 2017, 30,5\% of the industrial firms in the South was unable to receive new loans against the $24,6 \%$ of the Centre-northern ones. Moreover, the percentage of enterprises that, despite being interested in obtaining credit did not related to bank system thinking credit request would have been rejected, reaches the $57,4 \%$ in the South, versus the $40,2 \%$ in the Centre-north.

TABLE 3

FIRMS INVOLVED IN A HIGHER INDEBTNESS

\begin{tabular}{|c|c|c|c|c|c|c|c|c|}
\hline \multicolumn{9}{|c|}{ Industry } \\
\hline & \multicolumn{7}{|c|}{$\begin{array}{l}\text { Firms to which the request of new loans has completely or partially } \\
\text { been denied }\end{array}$} & \multirow{2}{*}{$\begin{array}{c}\begin{array}{c}\text { Average } \\
\text { values }\end{array} \\
2011-2017 \\
\end{array}$} \\
\hline & 2011 & 2012 & 2013 & 2014 & 2015 & 2016 & 2017 & \\
\hline Centre- North & 37,4 & 34,6 & 28,1 & 28,6 & 16,9 & 13,1 & 13,4 & 24,6 \\
\hline \multirow[t]{3}{*}{ Southern Italy } & 42,8 & 42,9 & 38,3 & 31,5 & 24,9 & 16,8 & 16,2 & 30,5 \\
\hline & \multicolumn{7}{|c|}{$\begin{array}{l}\text { Firms interested in greater indebtedness that did not initiate contacts } \\
\text { with banks in the belief that they would have responded negatively }\end{array}$} & $\begin{array}{c}\text { Average } \\
\text { values }\end{array}$ \\
\hline & 2011 & 2012 & 2013 & 2014 & 2015 & 2016 & 2017 & $2011-2017$ \\
\hline Centre- North & 44,6 & 42,9 & 32,4 & 36,6 & 50,8 & 43,9 & 30,3 & 40,2 \\
\hline Southern Italy & 41,0 & 61,1 & 84,0 & 59,8 & 65,1 & 64,2 & 26,7 & 57,4 \\
\hline
\end{tabular}

Source: Our elaboration on data by Bank of Italy, Survey on industrial firms and services, 2018.

The deteriorated macroeconomic scenario worsened the quality of the credit during the crisis. Although in 2017 only $23 \%$ of 170 billion euro of NPL are in the Southern area, they account for $14,3 \%$ of the total loans of the Southern economy, against the $8,4 \%$ of the Centre-north loans. Based on Cerved data elaborations, after reaching a maximum of 5,1\% in the years 2014-2015, in 2017, the rate of new NPL in the South, is still $+1,7 \%$ higher than in the Centre-North.

Besides the volumes of credit to the productive system, it is important to consider its cost that clearly reflects the riskiness of the operations of financing granted from the banks to the firms; such conditions reflect the coefficients of risk that the banks consider as assets requisite. Moreover, the relative discrepancy - calculated by considering the difference between the short-term interest rate in the South and in the Centre-north - fluctuated around the 17\% in 2008, increasing until the 30\% between 2010 and 2013 and touching $44 \%$ in 2015, and then oscillating around 40\% in the following two years, as shown in TABLE 4. 
TABLE 4

SHORT TERM INTEREST RATES DIFFERENTIAL (\%VALUES)

\begin{tabular}{|c|ccc|c|}
\hline Years & Centre-North $(\mathrm{CN})$ & Southern Italy $(\mathrm{SI})$ & Italy & $(\mathrm{SI}-\mathrm{CN}) /$ Italy *100 \\
\hline 2007 & 7,0 & 8,2 & 7,2 & 16,7 \\
2008 & 7,0 & 8,2 & 7,1 & 16,9 \\
2009 & 4,7 & 5,9 & 4,9 & 24,5 \\
2010 & 4,6 & 6,0 & 4,7 & 29,8 \\
2011 & 5,5 & 7,1 & 5,6 & 28,6 \\
2012 & 5,7 & 7,4 & 5,9 & 28,8 \\
2013 & 6,2 & 8,0 & 6,5 & 27,7 \\
2014 & 5,6 & 7,6 & 5,9 & 34,1 \\
2015 & 4,8 & 7,0 & 5,0 & 44,0 \\
2016 & 4,4 & 6,1 & 4,6 & 37,4 \\
2017 & 3,9 & 5,5 & 4,1 & 39,0 \\
\hline
\end{tabular}

Source: Our Elaboration Bank of Italy data.

Furthermore, if we take into account the interest rate differences within two macro-areas and firm size, some very remarkable differences arise, thus highlighting a criticism linked to the middlemen availability to finance the productive system: for instance, the interest rate applied to medium-large enterprises in Trentino-Alto Adige in 2017 has been equal to 3,1\%, while a rate of $9 \%$ has been applied to the small firms in Calabria. In conclusion, these data confirm that there are many criticism under the conditions of access to credit for the Southern enterprises - this phenomenon was partly broadened by the transformations of the banking system since the past decade and subsequently increased during the recent years, in terms of both the volumes of credit allocated and the practiced rates.

It is also evident that the most permissive conditions of the monetary policy practised by the BCE during this period have not been translated in a reduction in the interest rates imposed by banks to the enterprises, since these latter have incorporated increasing coefficients of risk that have more than compensated such reductions, especially in the Southern Italy.

\section{SOME PROPOSALS FOR THE RESHAPING OF A VIRTUOUS RELATIONSHIP BETWEEN BANK AND FIRM}

The long financial crisis that Europe has run over in these years has brought up the matter of heterogeneity between countries and regions of the Eurozone concerning credit, that sill represents a major cause for concern with respect to the perspectives of development of Eurozone countries and regions.

Besides, the supervisory model, established after the revision of Basel agreements and the interventions of $\mathrm{BCE}$, is marked by the imposition of stricter constraints to all the categories of intermediaries. Dealing with capitalisation, liquidity and risk management, from a microeconomic perspective, they should allow a greater resilience against adverse scenarios.

On the other side, from the macroeconomic point of view, there is no doubt that that this framework raises some problems. In fact, it imposes constraints to banks such that they become unable to support firms through credit provision, as it would be necessary to spur economic long-lasting growth and to favour a virtuous relationship among banks and firms. In the end, this approach prevents banking system enhancement in the long period.

In other words, when increasing bank capital requirements, supervisory authorities should carefully take into account the possible feedback effects between changes in regulatory capital and the 
macroeconomy: in a low-growth environment, regulatory pressures induce banks to tighten credit supply and reduce real GDP, which, in turn, exert pressure on banks to strengthen their capital position, thus reinforcing the initial negative effects on credit supply and economic activity. Moreover, this negative feedback may affect the transmission of monetary policy, possibly crowding out the effectiveness of expansionary measures, and should be thus considered also by central banks.

These are foreground critical issues in countries characterized by territorial unbalances that have dramatically increased in the last decade, like Italy. In fact, the reluctance to expand bank credit supply, even with a view to economic growth, derives from the increasingly more rigid constraints on capital adequacy and from the more automatic rules of customers rating determination. These constraints will be hardly able to support credit provision to those enterprises characterized by relatively higher risk profiles. The financial ties have become stricter, up to determine extremely problematic situations for the enterprises working in a more fragile territorial and institutional contexts, therefore exposed to greater risks, as in the case of Southern Italy.

It cannot be overlooked that Italy's fundamental problem is to be a dualistic economy; just think that the per capita income in the South is $60 \%$ of that in the Centre-North; there is a productivity gap of $17 \%$ and an employment rate which is $30 \%$ lower in the South than in the rest of Italy. In addition, Southern Italy shares with the rest of the country some problems: a low rate of firm's internationalization, lack of infrastructure and insufficient Foreign Direct Investments (FDI) attraction.

All these elements make the production system intrinsically more fragile, more risky and therefore less susceptible to being adequately financed by the banking system; in other words, the problem of moral hazard and adverse selection raises the firms riskiness and causes credit rationing phenomena we have seen in the previous paragraph which are more serious in the weak areas of the country. The crucial point is to propose a policy that raises the productivity and competitiveness of the production system and reduces the degree of risk thus allowing banks to finance investment projects, in compliance with the constraints imposed by banking supervision. The problem, as we have seen, is certainly more serious in the South, but concerns the whole country.

In fact, it should not be ignored that Southern Italy economy is characterized by a weaker institutional context and by a fragmented productive system, less involved in the processes of internationalization and more conditioned by the dynamics of the domestic market; clearly, bank credit stands as the only source of practicable financing for these enterprises. Then, until internal demand continues to be stagnating, the possibility of expansion for this area will be reduced and the risk profiles of the enterprises will subsequently increase. This will further undermine the relationship with the banking system, which, as observed, is already suffering for the heavy burden of NPL. The adoption of measures able to affect aggregate demand stands as one of the priority actions to undertake; consistently with public budget constraints, the implementation of public investment policy privileging Southern regions stands as a strategic option for the whole country. In fact, boosting internal demand can generate multiplier effects, thus strengthening internal market and, subsequently, local production system that relies on it. Since it can improve risk profiles, the process of strengthening this part of the productive system it could be further supported by bank credit (SVIMEZ, 2018, pp. 102-106).

Another potential economic policy course concerns the enhancement of enterprises, especially the most dynamic ones with greater international projection. From this point of view, the "special economic zones" (ZES) need to be carefully considered; indeed, these tools could represent an important chance to develop Southern Italy economy, to attract foreign investment and support the internationalization of the most dynamic component of Southern productive system, already existing in the South despite being reduced in dimensions.

Finally, the problem is to set up measures allowing forms of productive activity financing alternatives to the banking credit. The difficulties of accessing credit, that Southern enterprises face, appear more serious with reference to bond issues and stock quotations. These two funding channels have been targeted by several regulatory measures, aiming at making them available to smaller firms, and at simplifying and reducing access procedures and the relative costs. Thanks to such actions, the use of such 
channels from the SMEs has grown in recent years, albeit slowly; however, their dissemination has almost entirely occurred in the Centre-north.

One of the most critical issues preventing SMEs access to the non-banking funding tools in Italy is their low level of capitalization: for this reason, fiscal instruments could be used to encourage companies to set aside profits by allocating them to increase reserves or capital. Nevertheless, it must be observed that differently from other countries, in Italy, financial support to enterprises, especially the small ones, has not been developed into an fully comprehensive industrial policy framework aiming at supporting enterprises located in determined regions and operating in sectors held strategic for the development of the less developed territories. Therefore, the effectiveness of these provisions results very modest and weaker than the expected results. It can therefore be assumed that an effective development policy requires not only resources, but a clear national vision based on the interaction between institutions, infrastructures and the market.

\section{ENDNOTE}

1. The regional branches of the Bank of Italy conduct a survey on demand and supply of credit twice a year and on the trend of bank funding at the regional level (Regional Bank Lending Survey, RBLS) which largely reproduces the questions contained in the similar survey (BLS) carried out by the Euro system. With respect to the latter, the RBLS is characterized by the territorial and sectoral detail, the different temporal profile (half-yearly instead of quarterly) and for the greater number of banks involved (about 370), which allows to process information also due to the size of the intermediary. For more details see: https://www.bancaditalia.it/pubblicazioni/economie-regionali/index.html. 


\section{REFERENCES}

Arbolino, R., \& Marani, U. (2018). Crisi economica, resilienza e nuovi dualismi regionali, Rivista Economica Del Mezzogiorno, 32(1-2), 97-116.

Banca Centrale Europea. (2018). Addendum alle Linee guida della BCE per le banche sui crediti deteriorati (NPL): aspettative di vigilanza in merito agli accantonamenti prudenziali per le esposizioni deteriorate, March.

Banca d'Italia. (2018a). Economie Regionali.

Banca d'Italia. (2018b). Rapporto sulla Stabilità Finanziaria, 1, Aprile.

Barucci, E., \& Milani, C. (2017), Quali effetti da Basilea IV? FinRiskAlert, Newsletter, 35, 16 dicembre.

Basel Committee on Banking Supervision. (2009). Strengthening the resilience of the banking sector, Consultative Document December. BIS, Basel.

Basel Committee on Banking Supervision. (2010). An Assessment of the Long-Term Impact of Stronger Capital and Liquidity Requirements, Consultative Document August. BIS, Basel.

Consiglio Europeo. (2017). Conclusioni del Consiglio sul piano di azione per affrontare la questione dei crediti deteriorati in Europa. Comunicato stampa, 11 luglio.

Conti, A.M., Nobili, A., \& Signoretti, F.M. (2018). Bank capital constraints, lending supply and economic activity. Banca d'Italia, Temi di discussione, 1199, november.

Dixon, R., \&Thirlwall, A.P. (1975). A Model of Regional Growth-Rate Differences on Kaldorian Lines. Oxford Economic papers, New Series, 27(2), 201-214.

Europen Commission. (2017), Development of Secondary Markets for Non-Performing Loans and Distressed Assets and Protection of Secured Creditors from Borrowers' Default. Consultation Document, Bruxelles.

Imbriani, C. (2003). Banking system and the dualistic development of the Italian economy. In The Italian Economy at the Dawn of the XXI Century, M. Di Matteo, P. Piacentini (edited by), Aldershot: Ashgate.

Imbriani, C. (2011). Crisi, globalizzazione e problemi condivisi nel dualismo italiano. Rassegna Economica, 74(1), 51-76.

Imbriani, C., \& Lopes, A. (2016). Rischio e accesso al credito “ai tempi della crisi”. Il caso dell'Eurozona e del Mezzogiorno, Rassegna Economica, 79(1), 17-39.

Imbriani, C., \& Lopes, A. (2017). Sistemi bancari in Italia e Germania: vincoli nella politica dell'integrazione europea e capitalismo relazionale. Rassegna Economica, 80(2), 21-59.

Imbriani, C. \& Lopes, A. (2018). Effetti della crisi, dei requisiti di capitale e del rischio in una struttura economica dualistica. Rivista Economica Del Mezzogiorno, 32(1-2), 7-50.

Kaldor, N. (1970). The Case for Regional Policies. Scottish Journal of Political Economy, 7(3), 337-348.

Krugman, P. (1991). Increasing Returns and Economic Geography. Journal of Political Economy, 99(3), 483-499.

Krugman, P., \& Venables, A.J. (1990). Integration and the Competitiveness of Peripheral Industry. CEPR Discussion Papers, 363.

Krugman, P., \& Venables, A.J. (1995). Globalization and the Inequality of Nations. The Quarterly Journal of Economics, 110(4), 857-880.

Masera, R. (2016). Verso Basilea 4: le criticità per le banche e l'economia. Bancaria, 71(1), 2-17.

Myrdal, G. (1957). Economic Theory and Underdeveloped Regions. London: Methuen.

Myrdal, G. (1958). Rich Lands and Poor: The Road to World Prosperity. New York: Harper and Row.

SVIMEZ. (2018). Rapporto sull'economia e la società del Mezzogiorno. Bologna: Il Mulino. 